\title{
Targeting Glia with N-Acetylcysteine Modulates Brain Glutamate and Behaviors Relevant to Neurodevelopmental Disorders in C57BL/6J Mice
}

\author{
Alice M. S. Durieux ${ }^{1 \dagger}$, Cathy Fernandes ${ }^{2 \dagger}$, Declan Murphy ${ }^{1}$, Marie Anais Labouesse ${ }^{3}$, \\ Sandra Giovanoli ${ }^{3,4}$, Urs Meyer ${ }^{3,4}, \mathrm{Qi} \mathrm{Li}^{5}, \mathrm{Po}$-Wah So ${ }^{6 * \neq}$ and Grainne McAlonan ${ }^{1 * \neq}$ \\ 1 Department of Forensic and Neurodevelopmental Sciences, Institute of Psychiatry, Psychology and Neuroscience, King's \\ College London, London, UK, ${ }^{2}$ Social, Genetic and Developmental Psychiatry Centre, Institute of Psychiatry, Psychology and \\ Neuroscience, King's College London, London, UK, ${ }^{3}$ Physiology and Behaviour Laboratory, Swiss Federal Institute of \\ Technology, Schwerzenbach, Switzerland, ${ }^{4}$ Institute of Pharmacology and Toxicology, University of Zurich-Vetsuisse, Zurich, \\ Switzerland, ${ }^{5}$ Department of Psychiatry, Li Ka Shing Faculty of Medicine, The University of Hong Kong, Hong Kong, China, \\ ${ }^{6}$ Department of Neuroimaging, Institute of Psychiatry, Psychology and Neuroscience, King's College London, London, UK
}

\section{OPEN ACCESS}

Edited by:

Raymond C. K. Chan, Chinese Academy of Sciences, China

Reviewed by: Sebastian Herbert Scharf,

F. Hoffmann-La Roche Ltd,

Switzerland

Therese Van Amelsvoort, Maastricht University, Netherlands

*Correspondence:

Po-Wah So

po-wah.so@kcl.ac.uk;

Grainne McAlonan

grainne.mcalonan@kcl.ac.uk

tThese authors have contributed equally to this work.

\#Both authors are joined senio authors.

Received: 08 September 2015 Accepted: 23 November 2015 Published: 14 December 2015

Citation:

Durieux AMS, Fernandes $C$ Murphy D, Labouesse MA, Giovanoli S, Meyer U, Li Q, So P-W and McAlonan G (2015) Targeting Glia with N-Acetylcysteine Modulates Brain Glutamate and Behaviors Relevant to Neurodevelopmental Disorders in C57BL/6J Mice.

Front. Behav. Neurosci. 9:343. doi: 10.3389/fnbeh.2015.00343
An imbalance between excitatory (E) glutamate and inhibitory (I) GABA transmission may underlie neurodevelopmental conditions such as autism spectrum disorder (ASD) and schizophrenia. This may be direct, through alterations in synaptic genes, but there is increasing evidence for the importance of indirect modulation of $E / I$ balance through glial mechanisms. Here, we used C57BL/6J mice to test the hypothesis that striatal glutamate levels can be shifted by N-acetylcysteine (NAC), which acts at the cystineglutamate antiporter of glial cells. Striatal glutamate was quantified in vivo using proton magnetic resonance spectroscopy. The effect of NAC on behaviors relevant to ASD was examined in a separate cohort. NAC induced a time-dependent decrease in striatal glutamate, which recapitulated findings of lower striatal glutamate reported in ASD. NACtreated animals were significantly less active and more anxious in the open field test; and NAC-treated females had significantly impaired prepulse inhibition of startle response. This at least partly mimics greater anxiety and impaired sensorimotor gating reported in neurodevelopmental disorders. Thus glial mechanisms regulate glutamate acutely and have functional consequences even in adulthood. Glial cells may be a potential drug target for the development of new therapies for neurodevelopmental disorders across the life-span.

Keywords: $\mathrm{N}$-acetylcysteine, magnetic resonance spectroscopy, glutamate, neurodevelopmental disorders, anxiety, prepulse inhibition

\section{INTRODUCTION}

Neurodevelopmental disorders such as autism spectrum disorder (ASD) and schizophrenia affect about 1\% of the population (Saha et al., 2005; Baron-Cohen et al., 2009). Their etiology is poorly understood, and treatments are limited. However, recent advances in research suggest an imbalance between excitatory (E) glutamate and inhibitory (I) GABA is a key pathophysiological 
feature that may explain both core and common comorbid symptoms such as anxiety (Rubenstein and Merzenich, 2003; Cortese and Phan, 2005; Lewis and Kim, 2009; Coghlan et al., 2012; Moghaddam and Javitt, 2012).

$\mathrm{E} / \mathrm{I}$ imbalance in neurodevelopmental conditions can arise directly via alteration in genes encoding glutamatergic receptors or synaptic adhesion proteins (Silverman et al., 2012, 2015; Spooren et al., 2012). For example, the synapse organizers Neurexins and their binding partner Neuroligins are crucial to the formation and maintenance of excitatory and inhibitory synapses. Abnormalities in the genes encoding these proteins have been reported in both ASD and schizophrenia (Bang and Owczarek, 2013), and animal models have confirmed their role in synaptic transmission and behaviors relevant to neurodevelopmental disorders (Graf et al., 2004; Dahlhaus and El-Husseini, 2010; Grayton et al., 2013).

However, synaptic gene abnormalities account for only a relatively small proportion of the neurodevelopmental spectrum (Devlin and Scherer, 2012); and there is increasing evidence that E/I balance can also be modulated by glial mechanisms (Di Benedetto and Rupprecht, 2013). The brain's glial support system includes astrocytes, which support and protect neurons; and microglia, the resident macrophages of the central nervous system. These cells are now appreciated to have a critical role in synapse development, maintenance and remodelling (Koyama and Ikegama), but can also influence excitatory and inhibitory synaptic transmission (Auld and Robitaille, 2003). For instance, astrocytes regulate brain levels of glutamate and GABA through the glutamate/glutamine cycle (Liang et al., 2006); and activated microglia release glutamate (Domercq et al., 2013). A role for glial cells in neurodevelopmental disorders is supported by reports of abnormalities in astrocyte gene expression in both ASD and schizophrenia (Fatemi et al., 2008; Bernstein et al., 2009); and an increased number of activated microglia in adults with ASD (Onore et al., 2012).

System $\mathrm{x}_{c}-$, the cysteine-glutamate antiporter found on the cell membrane of glia, is central to their influence on synaptic transmission. It can be stimulated by the compound $\mathrm{N}$-Acetylcysteine (NAC, an FDA approved drug) to increase glutamate in the extrasynaptic space, thereby activating presynaptic mGluR2/3, which in turn inhibit the synaptic release of glutamate (Baker et al., 2003; Moran et al., 2005; Dean et al., 2011; Kupchik et al., 2012). Therefore, in this study we administered NAC to standard "wild-type" laboratory C57BL/6J mice to provide proof-of-concept evidence that acute modulation of glia alters glutamate levels in vivo; and has functional (behavioral) consequences. We used proton magnetic resonance spectroscopy $\left({ }^{1} \mathrm{H}-\mathrm{MRS}\right)$ to quantify glutamate in the left striatum, as both structural and functional abnormalities in this area are well documented in neurodevelopmental disorders (Haznedar et al., 2006; Scott-Van Zeeland et al., 2010; Simpson et al., 2010; De La Fuente-Sandoval et al., 2011; Baez-Mendoza and Schultz, 2013; Naaijen et al., 2015). In a separate cohort we assessed prepulse inhibition of startle response (PPI), a measure of sensorimotor gating which is impaired in ASD and schizophrenia (Braff et al., 2001;
McAlonan et al., 2002; Kumari et al., 2003; Perry et al., 2007). We also measured anxiety in the open field arena, as this is a common comorbidity of neurodevelopmental disorders (Braga et al., 2013; Joshi et al., 2013; Matson and Cervantes, 2014).

\section{MATERIALS AND METHODS}

\section{Animals}

Two cohorts of C57BL/6J mice (Charles River, Margate, Kent, UK) aged 7-8 weeks were used in the study. Animals were acclimatized to our facilities for a week before beginning the experimental procedures, during which they were group housed (2-4 per cage) in Tecniplast cages $(32 \mathrm{~cm} \times 16$ $\mathrm{cm} \times 14 \mathrm{~cm}$ ) with sawdust (Litaspen premium, Datesand Ltd, Manchester), a cardboard shelter and additional bedding material (Sizzlenest, Datesand Ltd, Manchester) and maintained on a 12h/12 h light/dark cycle (07:00-19:00 h) at constant room temperature $\left(21^{\circ} \mathrm{C}\right)$ and humidity $(45 \%)$. The mice were fed a standard diet (Rat and Mouse \#1 Diet, Special Diet Services, Essex, UK) and provided with water ad libitum. Both sexes were used in this study to avoid sex specific confounds. The oestrous phase of the female mice was not checked in this study. However, it is unlikely that this affected results because there were no major effects in the variance between males and females. All housing and experimental procedures were performed in compliance with the local ethical review panel of King's College London, and the UK Home Office Animals Scientific Procedures Act 1986. The work was carried out under license (PPL: 70/7184) and all efforts were made to minimize animal suffering and to reduce the number of animals used.

\section{Drug Treatment}

NAC was purchased from Sigma-Aldrich (UK), and dissolved in saline. Prior to experimental procedures, mice were injected (i.p.) with either $150 \mathrm{mg} / \mathrm{kg}$ NAC solution (30 g/L); injection volume approximately $100 \mathrm{microL}$ or vehicle (saline).

\section{Proton Magnetic Resonance Spectroscopy of the Brain}

In cohort I, 32 animals (16/sex) were treated with either NAC or vehicle, 115-175 min before data acquisition began. Animals were anaesthetized throughout the scan using an isofluorane/oxygen mix ( $5 \%$ induction, $2 \%$ maintenance). Body temperature and respiratory frequency were monitored and carefully regulated throughout the procedure.

Data were acquired on a 7T horizontal bore scanner (Agilent Technologies Inc., Walnut Creek, CA, USA) using a $33 \mathrm{~mm}$ internal diameter quadrature volume coil (Rapid Biomedical, Rimpar, Germany). The field was shimmed to $<14 \mathrm{MHz}$, width at half height of the water peak. Pilot MR images for voxel positioning were acquired using a fast spin-echo sequence with ${\text { repetition } \text { time }_{(T R)}=1000 \mathrm{~ms} \text {, effective echo time }}_{(T E)}=60 \mathrm{~ms}$, field of view $20 \times 20 \mathrm{~mm}, 27$ contiguous axial slices of $0.5 \mathrm{~mm}$ thickness, and two averages. These MR images were used for 
placement of a voxel $(2.2 \times 1.3 \times 1.9 \mathrm{~mm})$ in the left striatum for localized ${ }^{1} \mathrm{H}$-MRS as shown in Figure 1A. Point-RESolved Spectroscopy (PRESS; Bottomley, 1987) was used to acquire ${ }^{1} \mathrm{H}-\mathrm{MRS}$ data from the voxel with acquisition parameters: TR, $3000 \mathrm{~ms}$; TE, $24 \mathrm{~ms}$; 2048 data points; spectral width, $5208 \mathrm{~Hz}$ and 1000 averages. Water suppression was achieved using VAriable Pulse Power and Optimized Relaxation delays (VAPOR; Griffey and Flamig, 1990). PRESS was performed again but without water suppression with the same parameter values except collecting only eight averages from the same voxel.

Each spectrum was visually reviewed to ensure adequate signal to noise ratio, as well as the absence of artifacts. Spectra were analyzed using LCModel version 6.3-0I (Provencher, 1993) using a basis set of 21 metabolites including creatine $(\mathrm{Cr})$ and glutamate $(\mathrm{Glu})$. Model metabolites and concentrations used in the basis set are fully detailed in the LCModel manual (http://s-provencher.com/pages $/ \mathrm{lcm}$ manual.shtml). Poorly fitted metabolite peaks (Cramer-Rao minimum variance bounds of $>20 \%$ as reported by LCModel) were excluded from further analysis.

\section{Behavioral Testing}

In cohort II, 42 animals (20 males and 22 females) were treated with either NAC or vehicle $130 \mathrm{~min}$ prior to the assessment of open field locomotor activity. Animals were brought back to their home-cage for 10-15 min, and then PPI was performed 155 min post-treatment. Behavioral testing was carried out under stringent environmental control of housing and husbandry as well as the handling of the mice, balance and uniformity in testing, the experimenter, test location and standardized test procedures. Behavioral testing was conducted in the light phase of the light/dark cycle. After each individual test, boli and urine were removed from the test arena which was cleaned with $1 \%$ Anistel ${ }^{\circledR}$ solution (high level surface disinfectant, Trisel Solution Ltd, Cambridgeshire, UK) to remove any odors. Experimenters were blind to experimental treatment group during the testing.

\section{Open Field Locomotor Activity}

Locomotor activity in a novel open field area was assessed as a measure of anxiety as previously published (Grayton et al., 2013). Animals were placed in a square $40 \times 40 \mathrm{~cm}$ arena under white light (8 lux) for $10 \mathrm{~min}$ and video recorded. The central $(20 \times 20 \mathrm{~cm})$ and peripheral outer (remaining) areas of the arena were defined and movements in each zone were tracked with Ethovision software version 3.1 (Noldus Information Technologies bv, Wageningen, Netherlands). Time spent in the central zone was used as measure of anxiety, and distance travelled in the arena was used as measure of locomotor activity.

\section{Prepulse Inhibition of the Acoustic Startle Response}

PPI was assessed using a chamber for mice which recorded startle response amplitude (San Diego Instruments, San Diego, CA, USA), following a previously well-validated protocol (Vuillermot et al., 2011; Labouesse et al., 2013). Animals were placed in the Plexiglas enclosure and presented with a series of discrete trials. Four different trial types were used, including pulse alone trials, prepulse alone trials, prepulse-pulse trials and no-stimulus trials (where no sound was played other than the constant background noise). The pulse and prepulse stimuli consisted of a sudden elevation of the broadband white noise from the background level of $65 \mathrm{~dB}_{\mathrm{A}}$ with a rise time of $0.2-1 \mathrm{~ms}$, for 40 and $20 \mathrm{~ms}$ respectively. Three pulse intensities $(100,110$ and 120 $\mathrm{dB}_{\mathrm{A}}$ ), and three prepulse intensities $\left(71,77\right.$ and $83 \mathrm{~dB}_{\mathrm{A}}$ - which corresponded to 6,12 and $18 \mathrm{~dB}_{\mathrm{A}}$ above the background noise respectively) were used. The onset of the pulse was presented 100 $\mathrm{ms}$ after the onset of the prepulse, for all prepulse-pulse trials.

Animals were allowed to adapt to the enclosure for $2 \mathrm{~min}$ before the beginning of the first trial. They were presented with six pulse only trials (two trials of each intensity) for habituation, which were not included in the analysis. The test phase consisted of 10 blocks of 16 discrete trials. Each block included three pulse alone trials $\left(100,110\right.$ and $\left.120 \mathrm{~dB}_{\mathrm{A}}\right)$, three prepulse alone
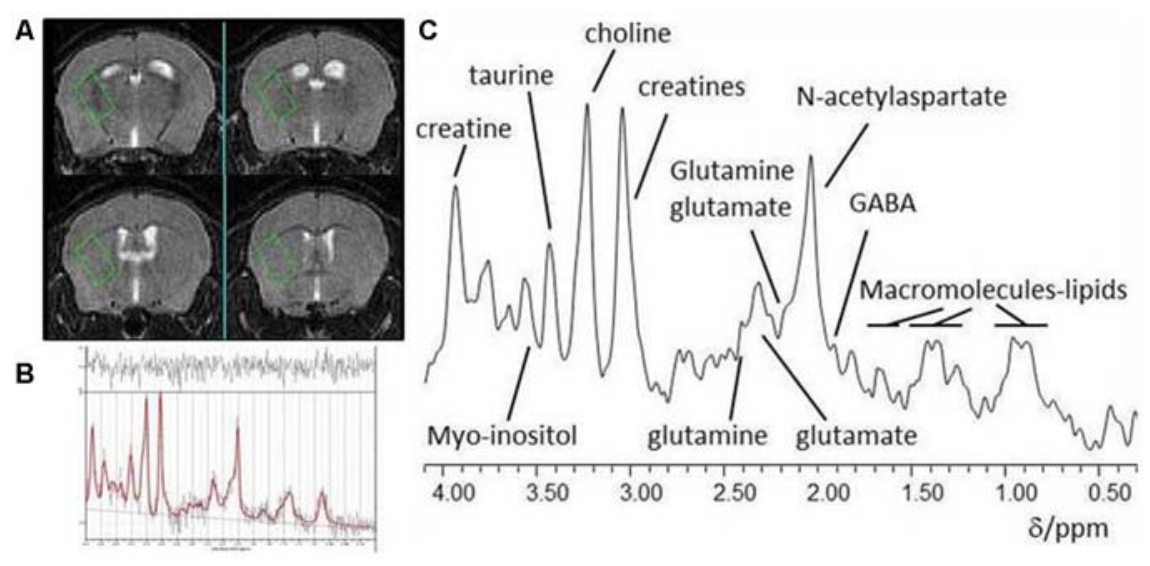

FIGURE 1 | (A) Typical placement of a striatal voxel on T2-weighted pilot MR images of the mouse brain; (B) In vivo localized ${ }^{1} \mathrm{H}-\mathrm{MR}$ spectrum from a striatal voxel and (C) LCModel analysis of a ${ }^{1} \mathrm{H}$ MR spectrum. 
trials $\left(71,77\right.$ and $83 \mathrm{~dB}_{\mathrm{A}}$ ), nine prepulse-pulse trials (all possible prepulse-pulse combinations), and one no-stimulus trial. Within each block, the 16 trials were presented in pseudorandom order and separated by a variable interval of 10-20 s (average $15 \mathrm{~s}$ ).

For each trial type, average reactivity was calculated over the whole experiment, excluding the first six pulse alone trials. PPI was measured as the percent inhibition of startle response (\%PPI) in pulse only trials. For each animal, it was calculated as follows: [(mean reactivity on pulse alone trials) - (mean reactivity on prepulse-pulse trials)/(mean reactivity on pulse alone trials)] * 100; for each pulse intensity $\left(100,110\right.$ and $\left.120 \mathrm{~dB}_{\mathrm{A}}\right)$, and each prepulse intensity $\left(71,77\right.$ and $\left.83 \mathrm{~dB}_{\mathrm{A}}\right)$.

\section{STATISTICAL ANALYSIS}

${ }^{1} \mathrm{H}-\mathrm{MRS}$ and open field data were analyzed using a general linear model (IBM SPSS Statistics version 21) including group and sex as between subject factors. The time postdose, $t_{\text {post-dose }}$ was included as covariate in the analysis of metabolite concentrations, and correlations between metabolite concentrations and $t_{\text {post-dose }}$ were explored using Pearson correlation coefficients.

For PPI analysis, reactivity to pulse alone trials were analyzed in a $3 \times 2 \times 2$ repeated measures ANOVA (pulse level $\times$ group $\times$ sex). \%PPI data were analyzed in $3 \times 3 \times 2 \times 2$ repeated measure ANOVA (prepulse level $\times$ pulse level $\times$ group $\times$ sex). Where there was a significant interaction between sex and another factor on \%PPI, data were re-analyzed separately for each sex.

\section{RESULTS}

\section{Localized ${ }^{1} \mathrm{H}$-MRS of the Brain}

\section{Creatine (Cr)}

A representative ${ }^{1} \mathrm{H}$-MRS spectrum of the left striatum is shown in Figures 1B,C. There was no main effect of treatment or sex on creatine (from creatine and phosphocreatine; all $F_{(1,26)}<$ 0.3 , all $p>0.6$ ). All subsequent metabolite concentrations were therefore calculated in reference to $\mathrm{Cr}$ to account for potential inter-individual differences in voxel composition (Gussew et al., 2012).

\section{Glutamate (Glu)}

$\mathrm{Glu} / \mathrm{Cr}$ concentrations were significantly lower in the NAC treated group, as indicated by a main effect of treatment $\left(F_{(1,26)}=\right.$ $5.77, p=0.02)$. There was also a main effect of $\mathrm{t}_{\text {post-dose }}$ on $\mathrm{Glu} / \mathrm{Cr}$ $\left(F_{(1,26)}=10.2, p=0.004\right)$. Furthermore Glu/Cr was negatively correlated with $t_{\text {post-dose }}$ in the NAC group $(r=-0.657, p=$ $0.008)$, but not in the vehicle group $(r=-0.417, p=0.108)$; as there was no main effect of sex on Glu/Cr, both sexes were examined together for the correlation analysis. Please refer to Figure 2 .

\section{Open Field Locomotor Activity}

\section{Distance Travelled}

There were main effects of treatment $\left(F_{(1,38)}=4.90, p=0.033\right)$ and $\operatorname{sex}\left(F_{(1,38)}=17.98, p<0.001\right)$ on distance travelled in the

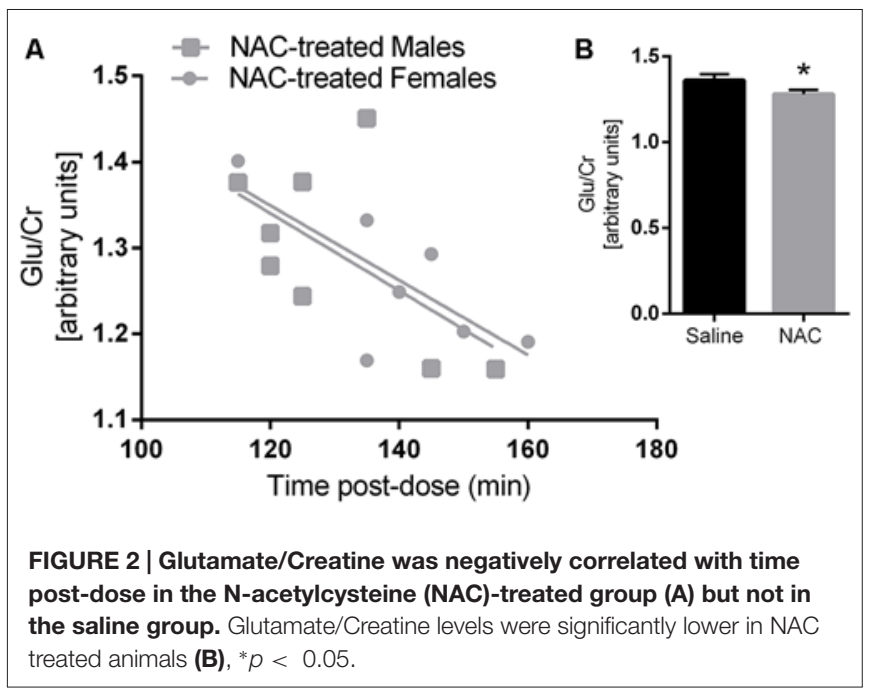

arena of the open field, and no sex $x$ treatment interaction. NAC treated mice travelled significantly less than their saline treated counterparts. Overall females travelled less distance than males (please refer to Figure 3A).

\section{Time in Central Zone}

As shown in Figure 3B, there was a main effect of treatment on time spent in central zone $\left(F_{(1,38)}=8.22, p=0.007\right)$, but no main effect of sex and no sex $\times$ treatment interaction. NAC treated animals spent significantly less time in the central zone. This treatment main effect remained significant when co-varying for distance travelled $\left(F_{(1,37)}=8.39, p=0.006\right)$, which indicates that the difference was not likely to be due to a change in locomotor activity.

\section{Prepulse Inhibition (PPI) of the Acoustic Startle Response}

Mean reactivity was higher at higher pulse intensity in pulse alone trials, as indicated by a mains effect of pulse intensity $\left(F_{(1.8,67.7)}=689.4, p<0.001\right)$. There was also a main effect of sex on reactivity to pulse alone trials $\left(F_{(1,38)}=66.23, p<0.001\right)$, as well as a pulse $\times$ sex interaction $\left(F_{(1.8,67.7)}=41.4, p<0.001\right)$.

There was no main effect of treatment or sex on \%PPI. The treatment $\times$ sex interaction approached significance $\left(F_{(1,38)}\right.$ $=3.11, p=0.086)$, therefore the analysis was repeated in each sex separately (please refer to Figure 3C). There was no effect of treatment on \%PPI in males. However NAC treated females displayed a significant reduction in \%PPI compared with controls $\left(F_{(1,20)}=5.29, p=0.032\right)$. The disruption of PPI by NAC emerged independently of specific pulse and prepulse intensities, as shown by non-significant interactions of pulse and prepulse with treatment.

\section{DISCUSSION}

This study provided proof-of-concept evidence that glutamate levels and behavior can be altered acutely by extra-synaptic mechanisms targeting glial cells. Activation of system $\mathrm{x}_{\mathrm{c}}-$ by 


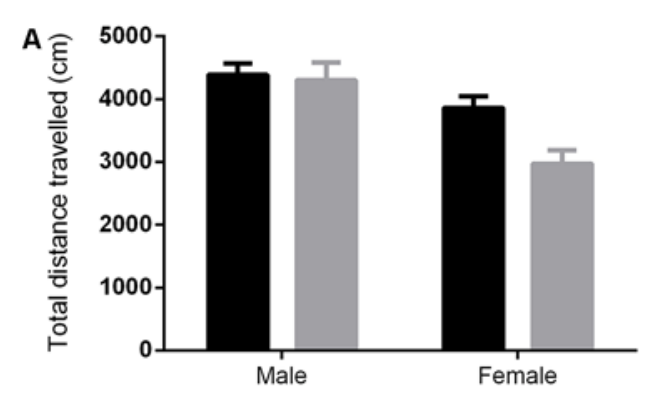

C
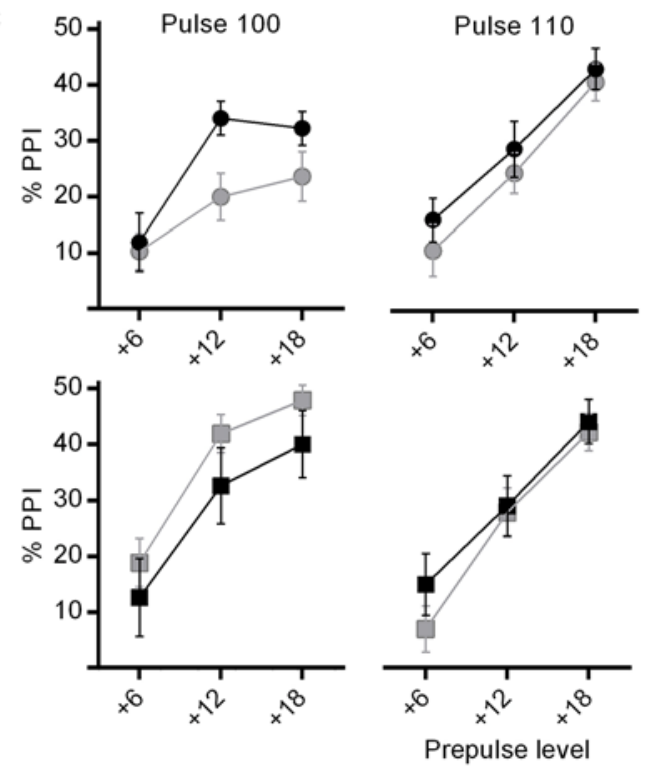

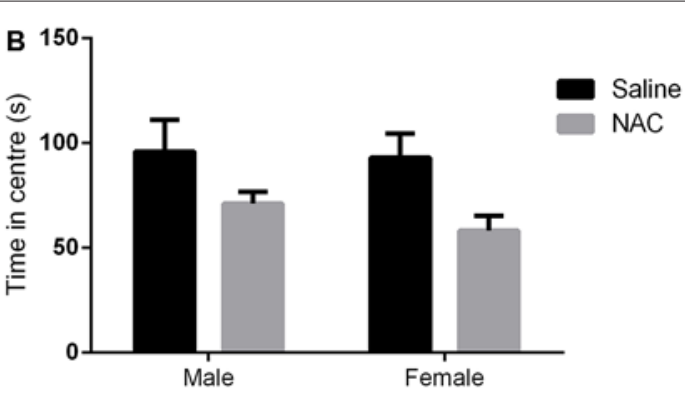

Pulse 120
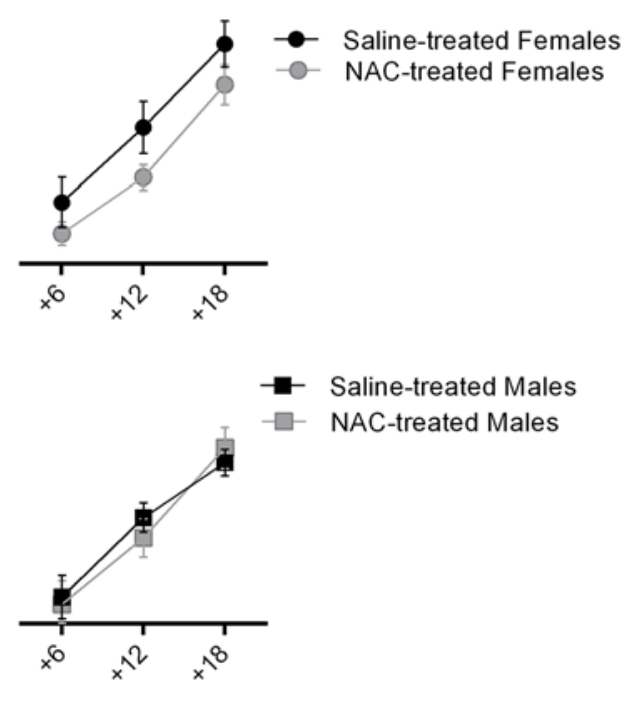

Saline-treated Males NAC-treated Males

( $\mathrm{dB}$ above background of $65 \mathrm{~dB}$ )

FIGURE 3 | NAC treatment reduced locomotor activity (main effect of treatment, $p=0.033$ ) $(A)$ and increased anxiety (main effect of treatment, $\boldsymbol{p}=\mathbf{0 . 0 0 7}$ (B), in females more than males. In (C), percent prepulse inhibition (\%PPI) is shown as a function of the three pulse levels (100, 110 or $120 \mathrm{~dB})$, and the three prepulse levels $\left(6,12\right.$ or $18 \mathrm{~dB}_{\mathrm{A}}$ above background level of $\left.65 \mathrm{~dB}_{\mathrm{A}}\right)$. \%PPI was reduced by NAC treatment in females only (main effect of treatment, $p=0.032)$.

NAC lowered glutamate concentrations in the striatum in a timedependent fashion. NAC-treated animals displayed reduced locomotor activity in the open field as well as increased anxiety, which was independent from general activity levels. NAC treatment reduced the prepulse inhibition of startle response in females exclusively.

The acute glutamatergic effects of NAC observed in this study are consistent with, and extend previous findings. For example previous studies showed that NAC reduces excitatory currents in an mGluR2/3 dependent fashion (Moran et al., 2005; Kupchik et al., 2012). One ${ }^{1} \mathrm{H}$-MRS study in a mouse model of schizophrenia found that chronic NAC treatment reduces cortical glutamate levels in developing animals (Das Neves Duarte et al., 2012). Here, we show that one dose of NAC is sufficient to lower striatal glutamate in a time-dependent fashion; the lowest glutamate levels are evident $120 \mathrm{~min}$ postdose and continue to decrease for at least $60 \mathrm{~min}$. We report that a single dose of NAC also disrupts behavior from $120 \mathrm{~min}$ post-administration. We interpret the behavioral differences as likely due to a glutamate decrease, but acknowledge the evidence is indirect. These findings may have translational importance as they suggest that targeting glia can shift glutamate levels; and this is relevant to neurodevelopmental disorders such as ASD and schizophrenia, where glial abnormalities and E/I imbalance are prominent features.

Our finding of reduced striatal glutamate is analogous to the decrease of glutamate and its metabolite glutamine observed in the striatum of adult males with ASD (Horder et al., 2013). Our observations of greater anxiety and impaired sensorimotor gating in NAC-treated animals also mimics impairments commonly found in ASD and related neurodevelopmental disorders (McAlonan et al., 2002; Perry et al., 2007; Braga et al., 2013; Joshi et al., 2013; Matson and Cervantes, 2014). Thus, although our design did not make it possible to assess glutamate levels and behavior in the same animals, behavioral findings may well relate to a change in glutamate concentrations.

For example, locomotor activity, anxiety and PPI at least partly depend on glutamatergic transmission (Takeuchi et al., 
2001; O'Neill et al., 2003; Wieronska and Pilc, 2013; Saitoh et al., 2014). Here, we report that indirect $\mathrm{mGluR} 2 / 3$ agonism via NAC causes lower activity. This is consistent with a role for $m G l u R 2 / 3$ in the tonic inhibition of locomotion; and the observation that mGluR2/3 antagonism increases locomotion (O'Neill et al., 2003). However, mGluR2/3 agonism has been reported to both increase (Imre et al., 2006; Satow et al., 2008) and decrease (Imre et al., 2006; Grivas et al., 2013) anxiety, depending on the dose. Similarly, acute administration of mGluR2/3 agonists has been reported to have either no effect (intra-peritoneal administration of LY379268; Hikichi et al., 2010), or impair (intracerebral administration of $L$ CCG-I; Grauer and Marquis, 1999), PPI. Thus, the mGluR2/3 response is likely to be complex and depend on the dose and administration regime of compounds targeting these receptors.

Although we show here that NAC administration mimics lower striatal glutamate and causes behavioral abnormalities similar to those found in ASD, paradoxically, NAC has shown clinical benefits in small scale double blind trials in this condition (Hardan et al., 2012; Ghanizadeh and MoghimiSarani, 2013). However, the latter study examined NAC as an adjunct alongside risperidone, and a recently completed Clinical Trial of NAC in ASD did not find evidence of efficacy ( $K$. Gray, personal communication). There are a number of possible explanations for these inconsistencies. First, the acute effects of NAC may be quite distinct from the effects of repeated administration in clinical settings. Arguably, the glutamate system responds differently to chronic modulation compared to acute challenge. Secondly, the developmental stage studied may be critical, as glutamate levels in humans are known to vary with age (Segovia et al., 2001; Kaiser et al., 2005). The clinical trials of NAC in ASD were mostly completed in children (Hardan et al., 2012; Ghanizadeh and MoghimiSarani, 2013), while we used adult animals. Third, the effects of NAC may be different in a "disordered" system. We used standard in-bred laboratory mice in this study; it is possible that the effects of NAC would be different in a mouse model showing baseline E/I imbalance. Some support for this latter suggestion comes from preliminary work in schizophrenia. NAC has shown benefits in adults with schizophrenia (Zavodnick and Ali, 2014), but a study in healthy volunteers found that NAC pretreatment worsened auditory mismatch negativity following ketamine administration (Gunduz-Bruce et al., 2012), a paradigm thought to mimic psychosis. Finally, it is possible that the clinical benefits of chronic administration of NAC are in fact mediated by its antioxidant actions, rather than its glutamatergic action (Dean et al., 2009; Rushworth and Megson, 2013). Thus, we emphasize that our findings do not speak to the therapeutic use of NAC in neurodevelopmental disorders, for which there is no clear consensus. Rather, we suggest that our finding shows that modulating glutamate and behavior via glial mechanisms is possible, and suggests that glial mechanisms may be a tractable target for drugs which aim to modulate $\mathrm{E} / \mathrm{I}$.

We acknowledge some unexpected findings in this study. We elected to study NAC in both female and male animals and found sex-differences in the PPI response following NAC administration. PPI is particularly sensitive to sex-differences in both laboratory animals (Lehmann et al., 1999; Ralph et al., 2001; Zhang et al., 2015) and individuals with neurodevelopmental disorders (Kumari et al., 2004; Gogos et al., 2009). Moreover, although there were no treatment $\times$ sex interactions in measures of activity and anxiety, the effects of NAC on these measures was numerically greater in females compared to males. It is therefore possible that female mice are more sensitive to the behavioral consequences of the change in glutamate, however larger sample sizes would be needed to explore this in more detail. It would also be valuable to determine whether there are any sex differences in glial mechanisms. We echo the call for more research into sex differences in neurodevelopmental disorders, particularly as it becomes apparent that their prevalence in females may be higher than thought previously (Brix et al., 2015). We also acknowledge that an important limitation of this study was that we did not measure glutamate levels and assess behavior in the same animals. The current design was chosen to avoid confounds related to putting the same animals through several experimental procedures sequentially. Previous work has shown that invasive behavioral testing could induce changes in neural activity patterns (Xu et al., 2012), and brain metabolite levels (Zhou et al., 2012). On the other hand, the imaging procedure, which required $2 \mathrm{~h}$ of anaesthesia, is a significant exposure and could impact upon subsequent behavioral testing. Therefore we chose to use a naïve cohort of mice animals for the behavioral and the imaging experiments. Future research will aim to correlate E/I and behavioral measures in the same animals, possibly using ex vivo methods. Finally, the PRESS spectroscopy acquisition protocol we used did not allow for estimation of GABA concentration. Glutamate and GABA are constantly in flux and measuring the other side of the E/I ratio would be useful to obtain a fuller picture in the future.

In summary, this work confirms that glial mechanisms regulate glutamate acutely and have functional consequences in adult animals. Glial cells may therefore be a potential drug target for the development of new therapies for neurodevelopmental disorders even in the adult system.

\section{AUTHOR CONTRIBUTIONS}

AMSD, GM, P-WS, CF, DM, QL, ML, SG and UM designed the research. AMSD, P-WS, CF, ML, SG and UM acquired the data. AMSD, GM, P-WS, CF, ML, QL, SG and UM analyzed the data. AMSD, GM, P-WS, CF, DM, ML, QL, SG and UM critically interpreted the data. AMSD and GM drafted the manuscript. AMSD, GM, P-WS, CF, DM, ML, QL, SG and UM approved the final version.

\section{FUNDING}

AMSD is supported by a $\mathrm{PhD}$ studentship from the National Institute for Health Research (NIHR) Biomedical Research Center at South London and Maudsley NHS Foundation Trust and King's College London. The views expressed 
are those of the author(s) and not necessarily those of the NHS, the NIHR or the Department of Health. This work was funded by the Sackler Institute for Translational Development.

\section{REFERENCES}

Auld, D. S., and Robitaille, R. (2003). Glial cells and neurotransmission: an inclusive view of synaptic function. Neuron 40, 389-400. doi: 10.1016/S08966273(03)00607-X

Baez-Mendoza, R., and Schultz, W. (2013). The role of the striatum in social behavior. Front. Neurosci. 7:233. doi: 10.3389/fnins.2013.00233

Baker, D. A., Mcfarland, K., Lake, R. W., Shen, H., Toda, S., and Kalivas, P. W. (2003). N-acetyl cysteine-induced blockade of cocaine-induced reinstatement. Ann. N. Y. Acad. Sci. 1003, 349-351. doi: 10.1196/annals.1300.023

Bang, M. L., and Owczarek, S. (2013). A matter of balance: role of neurexin and neuroligin at the synapse. Neurochem. Res. 38, 1174-1189. doi: 10.1007/s11064013-1029-9

Baron-Cohen, S., Scott, F. J., Allison, C., Williams, J., Bolton, P., Matthews, F. E., et al. (2009). Prevalence of autism-spectrum conditions: UK schoolbased population study. Br. J. Psychiatry. 194, 500-509. doi: 10.1192/bjp.bp. 108.059345

Bernstein, H. G., Steiner, J., and Bogerts, B. (2009). Glial cells in schizophrenia: pathophysiological significance and possible consequences for therapy. Expert Rev. Neurother. 9, 1059-1071. doi: 10.1586/ern.09.59

Bottomley, P. A. (1987). Spatial localization in NMR spectroscopy in vivo. Ann. N. Y. Acad. Sci. 508, 333-348. doi: 10.1111/j.1749-6632.1987.tb32915.x

Braff, D. L., Geyer, M. A., and Swerdlow, N. R. (2001). Human studies of prepulse inhibition of startle: normal subjects, patient groups and pharmacological studies. Psychopharmacology Berl. 156, 234-258. doi: 10.1007/s00213010 0810

Braga, R. J., Reynolds, G. P., and Siris, S. G. (2013). Anxiety comorbidity in schizophrenia. Psychiatry. Res. 210, 1-7. doi: 10.1016/j.psychres.2013.07.030

Brix, M. K., Ersland, L., Hugdahl, K., Gruner, R., Posserud, M. B., Hammar, A., et al. (2015). "Brain MR spectroscopy in autism spectrum disorder-the GABA excitatory/inhibitory imbalance theory revisited”. Front. Hum. Neurosci.9: 365. doi: 10.3389/fnhum.2015.00365

Coghlan, S., Horder, J., Inkster, B., Mendez, M. A., Murphy, D. G., and Nutt, D. J. (2012). GABA system dysfunction in autism and related disorders: from synapse to symptoms. Neurosci. Biobehav. Rev. 36, 2044-2055. doi: 10.1016/j. neubiorev.2012.07.005

Cortese, B. M., and Phan, K. L. (2005). The role of glutamate in anxiety and related disorders. CNS Spectr. 10, 820-830. doi: 10.1017/S10928529000 10427

Dahlhaus, R., and El-Husseini, A. (2010). Altered neuroligin expression is involved in social deficits in a mouse model of the fragile X syndrome. Behav. Brain Res. 208, 96-105. doi: 10.1016/j.bbr.2009.11.019

Das Neves Duarte, J. M., Kulak, A., Gholam-Razaee, M. M., Cuenod, M., Gruetter, R., and Do, K. Q. (2012). N-acetylcysteine normalizes neurochemical changes in the glutathione-deficient schizophrenia mouse model during development. Biol. Psychiatry. 71, 1006-1014. doi: 10.1016/s0920-9964(12)70162-7

De La Fuente-Sandoval, C., Leon-Ortiz, P., Favila, R., Stephano, S., Mamo, D., Ramirez-Bermudez, J., et al. (2011). Higher levels of glutamate in the associative-striatum of subjects with prodromal symptoms of schizophrenia and patients with first-episode psychosis. Neuropsychopharmacology 36, 1781-1791. doi: 10.1038/npp.2011.65

Dean, O., Giorlando, F., and Berk, M. (2011). N-acetylcysteine in psychiatry: current therapeutic evidence and potential mechanisms of action. J. Psychiatry. Neurosci. 36, 78-86. doi: 10.1503/jpn.100057

Dean, O. M., Van Den Buuse, M., Bush, A. I., Copolov, D. L., Ng, F., Dodd, S., et al. (2009). A role for glutathione in the pathophysiology of bipolar disorder and schizophrenia? Animal models and relevance to clinical practice. Curr. Med. Chem. 16, 2965-2976. doi: 10.2174/092986709788803060

Devlin, B., and Scherer, S. W. (2012). Genetic architecture in autism spectrum disorder. Curr. Opin. Genet. Dev. 22, 229-237. doi: 10.1016/j.gde.2012.03.002

\section{ACKNOWLEDGMENT}

Thanks to the British Heart Foundation for funding the purchase of the 7T MRI scanner used in the study.

Di Benedetto, B., and Rupprecht, R. (2013). Targeting glia cells: novel perspectives for the treatment of neuropsychiatric diseases. Curr. Neuropharmacol. 11, 171-185. doi: 10.2174/1570159x11311020004

Domercq, M., Vazquez-Villoldo, N., and Matute, C. (2013). Neurotransmitter signaling in the pathophysiology of microglia. Front. Cell. Neurosci. 7:49. doi: $10.3389 /$ fncel.2013.00107

Fatemi, S. H., Folsom, T. D., Reutiman, T. J., and Lee, S. (2008). Expression of astrocytic markers aquaporin 4 and connexin 43 is altered in brains of subjects with autism. Synapse 62, 501-507. doi: 10.1002/syn.20519

Ghanizadeh, A., and Moghimi-Sarani, E. (2013). A randomized double blind placebo controlled clinical trial of N-Acetylcysteine added to risperidone for treating autistic disorders. BMC Psychiatry. 13:196. doi: 10.1186/1471-244x13-196

Gogos, A., Van Den Buuse, M., and Rossell, S. (2009). Gender differences in prepulse inhibition (PPI) in bipolar disorder: men have reduced PPI, women have increased PPI. Int. J. Neuropsychopharmacol. 12, 1249-1259. doi: 10. $1017 /$ s1461145709000480

Graf, E. R., Zhang, X., Jin, S. X., Linhoff, M. W., and Craig, A. M. (2004). Neurexins induce differentiation of GABA and glutamate postsynaptic specializations via neuroligins. Cell 119, 1013-1026. doi: 10.1016/j.cell.2004.11.035

Grauer, S. M., and Marquis, K. L. (1999). Intracerebral administration of metabotropic glutamate receptor agonists disrupts prepulse inhibition of acoustic startle in Sprague-Dawley rats. Psychopharmacology (Berl) 141, 405-412. doi: 10.1007/s002130050850

Grayton, H. M., Missler, M., Collier, D. A., and Fernandes, C. (2013). Altered social behaviours in neurexin lalpha knockout mice resemble core symptoms in neurodevelopmental disorders. PLoS One 8:e67114. doi: 10.1371/journal. pone.0067114

Griffey, R., and Flamig, D. (1990). VAPOR for solvent-suppressed, short echo, volume-localized spectroscopy. J. Mag. Res. 88, 161-166. doi: 10.1016/00222364(90)90120-x

Grivas, V., Markou, A., and Pitsikas, N. (2013). The metabotropic glutamate $2 / 3$ receptor agonist LY379268 induces anxiety-like behavior at the highest dose tested in two rat models of anxiety. Eur. J. Pharmacol. 715, 105-110. doi: 10. 1016/j.ejphar.2013.05.048

Gunduz-Bruce, H., Reinhart, R. M., Roach, B. J., Gueorguieva, R., Oliver, S., D'souza, D. C., et al. (2012). Glutamatergic modulation of auditory information processing in the human brain. Biol. Psychiatry. 71, 969-977. doi: 10.1016/j. biopsych.2011.09.031

Gussew, A., Erdtel, M., Hiepe, P., Rzanny, R., and Reichenbach, J. R. (2012) Absolute quantitation of brain metabolites with respect to heterogeneous tissue compositions in (1)H-MR spectroscopic volumes. MAGMA 25, 321-333. doi: 10.1007/s10334-012-0305-Z

Hardan, A. Y., Fung, L. K., Libove, R. A., Obukhanych, T. V., Nair, S., Herzenberg, L. A., et al. (2012). A randomized controlled pilot trial of oral N-acetylcysteine in children with autism. Biol. Psychiatry. 71, 956-961. doi: 10.1016/j.biopsych. 2012.01.014

Haznedar, M. M., Buchsbaum, M. S., Hazlett, E. A., Licalzi, E. M., Cartwright, C., and Hollander, E. (2006). Volumetric analysis and three-dimensional glucose metabolic mapping of the striatum and thalamus in patients with autism spectrum disorders. Am. J. Psychiatry. 163, 1252-1263. doi: 10.1176/appi.ajp. 163.7.1252

Hikichi, H., Nishino, M., Fukushima, M., Satow, A., Maehara, S., Kawamoto, H., et al. (2010). Pharmacological effects of metabotropic glutamate receptor ligands on prepulse inhibition in DBA/2J mice. Eur. J. Pharmacol. 639, 99-105. doi: 10.1016/j.ejphar.2010.03.046

Horder, J., Lavender, T., Mendez, M. A., O'gorman, R., Daly, E., Craig, M. C., et al. (2013). Reduced subcortical glutamate/glutamine in adults with autism spectrum disorders: a [(1)H]MRS study. Transl. Psychiatry. 3:e279. doi: 10. 1038/tp.2013.53 
Imre, G., Salomons, A., Jongsma, M., Fokkema, D. S., Den Boer, J. A., and Ter Horst, G. J. (2006). Effects of the mGluR2/3 agonist LY379268 on ketamineevoked behaviours and neurochemical changes in the dentate gyrus of the rat. Pharmacol. Biochem. Behav. 84, 392-399. doi: 10.1016/j.pbb.2006.05.021

Joshi, G., Wozniak, J., Petty, C., Martelon, M. K., Fried, R., Bolfek, A., et al. (2013). Psychiatric comorbidity and functioning in a clinically referred population of adults with autism spectrum disorders: a comparative study. J. Autism. Dev. Disord. 43, 1314-1325. doi: 10.1007/s10803-012-1679-5

Kaiser, L. G., Schuff, N., Cashdollar, N., and Weiner, M. W. (2005). Age-related glutamate and glutamine concentration changes in normal human brain: $1 \mathrm{H}$ MR spectroscopy study at 4 T. Neurobiol. Aging. 26, 665-672. doi: 10.1016/j. neurobiolaging.2004.07.001

Kumari, V., Aasen, I., and Sharma, T. (2004). Sex differences in prepulse inhibition deficits in chronic schizophrenia. Schizophr. Res. 69, 219-235. doi: 10.1016/j. schres.2003.09.010

Kumari, V., Gray, J. A., Geyer, M. A., Ffytche, D., Soni, W., Mitterschiffthaler, M. T., et al. (2003). Neural correlates of tactile prepulse inhibition: a functional MRI study in normal and schizophrenic subjects. Psychiatry. Res. 122, 99-113. doi: 10.1016/s0925-4927(02)00123-3

Kupchik, Y. M., Moussawi, K., Tang, X. C., Wang, X., Kalivas, B. C., Kolokithas, R., et al. (2012). The effect of $\mathrm{N}$-acetylcysteine in the nucleus accumbens on neurotransmission and relapse to cocaine. Biol. Psychiatry. 71, 978-986. doi: 10. 1016/j.biopsych.2011.10.024

Labouesse, M. A., Stadlbauer, U., Langhans, W., and Meyer, U. (2013). Chronic high fat diet consumption impairs sensorimotor gating in mice. Psychoneuroendocrinology 38, 2562-2574. doi: 10.1016/j.psyneuen.2013. 06.003

Lehmann, J., Pryce, C. R., and Feldon, J. (1999). Sex differences in the acoustic startle response and prepulse inhibition in Wistar rats. Behav. Brain Res. 104, 113-117. doi: 10.1016/s0166-4328(99)00058-3

Lewis, M., and Kim, S. J. (2009). The pathophysiology of restricted repetitive behavior. J. Neurodev. Disord. 1, 114-132. doi: 10.1007/s11689-0099019-6

Liang, S. L., Carlson, G. C., and Coulter, D. A. (2006). Dynamic regulation of synaptic GABA release by the glutamate-glutamine cycle in hippocampal area CA1. J. Neurosci. 26, 8537-8548. doi: 10.1523/jneurosci.0329-06. 2006

Matson, J. L., and Cervantes, P. E. (2014). Commonly studied comorbid psychopathologies among persons with autism spectrum disorder. Res. Dev. Disabil. 35, 952-962. doi: 10.1016/j.ridd.2014. 02.012

McAlonan, G. M., Daly, E., Kumari, V., Critchley, H. D., Van Amelsvoort, T., Suckling, J., et al. (2002). Brain anatomy and sensorimotor gating in Asperger's syndrome. Brain 125, 1594-1606. doi: 10.1093/brain/awf150

Moghaddam, B., and Javitt, D. (2012). From revolution to evolution: the glutamate hypothesis of schizophrenia and its implication for treatment. Neuropsychopharmacology 37, 4-15. doi: 10.1038/npp.2011.181

Moran, M. M., Mcfarland, K., Melendez, R. I., Kalivas, P. W., and Seamans, J. K. (2005). Cystine/glutamate exchange regulates metabotropic glutamate receptor presynaptic inhibition of excitatory transmission and vulnerability to cocaine seeking. J. Neurosci. 25, 6389-6393. doi: 10.1523/jneurosci.1007-05. 2005

Naaijen, J., Lythgoe, D. J., Amiri, H., Buitelaar, J. K., and Glennon, J. C. (2015). Fronto-striatal glutamatergic compounds in compulsive and impulsive syndromes: a review of magnetic resonance spectroscopy studies. Neurosci. Biobehav. Rev. 52, 74-88. doi: 10.1016/j.neubiorev.2015. 02.009

O'Neill, M. F., Heron-Maxwell, C., Conway, M. W., Monn, J. A., and Ornstein, P. (2003). Group II metabotropic glutamate receptor antagonists LY341495 and LY366457 increase locomotor activity in mice. Neuropharmacology 45, 565-574. doi: 10.1016/s0028-3908(03) 00232-6

Onore, C., Careaga, M., and Ashwood, P. (2012). The role of immune dysfunction in the pathophysiology of autism. Brain Behav. Immun. 26, 383-392. doi: 10. 1016/j.bbi.2011.08.007

Perry, W., Minassian, A., Lopez, B., Maron, L., and Lincoln, A. (2007). Sensorimotor gating deficits in adults with autism. Biol. Psychiatry. 61, 482-486. doi: 10.1016/j.biopsych.2005.09.025
Provencher, S. W. (1993). Estimation of metabolite concentrations from localized in vivo proton NMR spectra. Mag. Res. Med. 30, 672-679. doi: 10.1002/mrm. 1910300604

Ralph, R. J., Paulus, M. P., and Geyer, M. A. (2001). Strain-specific effects of amphetamine on prepulse inhibition and patterns of locomotor behavior in mice. J. Pharmacol. Exp. Ther. 298, 148-155.

Rubenstein, J. L., and Merzenich, M. M. (2003). Model of autism: increased ratio of excitation/inhibition in key neural systems. Genes. Brain Behav. 2, 255-267. doi: 10.1034/j.1601-183x.2003.00037.x

Rushworth, G. F., and Megson, I. L. (2013). Existing and potential therapeutic uses for N-acetylcysteine: the need for conversion to intracellular glutathione for antioxidant benefits. Pharmacol. Ther. 141, 150-159. doi: 10.1016/j. pharmthera.2013.09.006

Saha, S., Chant, D., Welham, J., and Mcgrath, J. (2005). A systematic review of the prevalence of schizophrenia. PLoS Med 2:e141. doi: 10.1016/s09209964(14)70102-1

Saitoh, A., Ohashi, M., Suzuki, S., Tsukagoshi, M., Sugiyama, A., Yamada, M., et al. (2014). Activation of the prelimbic medial prefrontal cortex induces anxietylike behaviors via N-Methyl-D-aspartate receptor-mediated glutamatergic neurotransmission in mice. J. Neurosci. Res. 92, 1044-1053. doi: 10.1002/jnr. 23391

Satow, A., Maehara, S., Ise, S., Hikichi, H., Fukushima, M., Suzuki, G., et al. (2008). Pharmacological effects of the metabotropic glutamate receptor 1 antagonist compared with those of the metabotropic glutamate receptor 5 antagonist and metabotropic glutamate receptor $2 / 3$ agonist in rodents: detailed investigations with a selective allosteric metabotropic glutamate receptor 1 antagonist, FTIDC [4-[1-(2-fluoropyridine-3-yl)-5-methyl1H-1,2,3-triazol-4-yl]-N-isopropyl-N-methy 1-3,6-dihydropyridine-1(2H)carboxamide]. J. Pharmacol. Exp. Ther. 326, 577-586. doi: 10.1124/jpet.108. 138107

Scott-Van Zeeland, A. A., Dapretto, M., Ghahremani, D. G., Poldrack, R. A., and Bookheimer, S. Y. (2010). Reward processing in autism. Autism. Res. 3, 53-67. doi: 10.1186/2040-2392-3-7

Segovia, G., Porras, A., Del Arco, A., and Mora, F. (2001). Glutamatergic neurotransmission in aging: a critical perspective. Mech. Ageing Dev. 122, 1-29. doi: 10.1016/s0047-6374(00)00225-6

Silverman, J. L., Pride, M. C., Hayes, J. E., Puhger, K. R., Butler-Struben, H. M., Baker, S., et al. (2015). GABAB receptor agonist r-baclofen reverses social deficits and reduces repetitive behavior in two mouse models of autism. Neuropsychopharmacology 40, 2228-2239. doi: 10.1038/npp. 2015.66

Silverman, J. L., Smith, D. G., Rizzo, S. J., Karras, M. N., Turner, S. M., Tolu, S. S., et al. (2012). Negative allosteric modulation of the mGluR5 receptor reduces repetitive behaviors and rescues social deficits in mouse models of autism. Sci. Transl. Med. 4, 131ra151. doi: 10.1126/scitranslmed. 3003501

Simpson, E. H., Kellendonk, C., and Kandel, E. (2010). A possible role for the striatum in the pathogenesis of the cognitive symptoms of schizophrenia. Neuron 65, 585-596. doi: 10.1016/j.neuron.2010. 02.014

Spooren, W., Lindemann, L., Ghosh, A., and Santarelli, L. (2012). Synapse dysfunction in autism: a molecular medicine approach to drug discovery in neurodevelopmental disorders. Trends Pharmacol. Sci. 33, 669-684. doi: 10. 1016/j.tips.2012.09.004

Takeuchi, T., Kiyama, Y., Nakamura, K., Tsujita, M., Matsuda, I., Mori, H., et al. (2001). Roles of the glutamate receptor epsilon2 and delta2 subunits in the potentiation and prepulse inhibition of the acoustic startle reflex. Eur. J. Neurosci. 14, 153-160. doi: 10.1046/j.0953-816x.2001. 01620.x

Vuillermot, S., Feldon, J., and Meyer, U. (2011). Nurr1 is not essential for the development of prepulse inhibition deficits induced by prenatal immune activation. Brain Behav. Immun. 25, 1316-1321. doi: 10.1016/j.bbi.2011. 06.012

Wieronska, J. M., and Pilc, A. (2013). Glutamate-based anxiolytic ligands in clinical trials. Expert Opin. Investig. Drugs 22, 1007-1022. doi: 10. $1517 / 13543784.2013 .803066$

Xu, J. Y., Xia, Q. Q., and Xia, J. (2012). A review on the current neuroligin mouse models. Sheng. Li. Xue. Bao. 64, 550-562. 
Zavodnick, A. D., and Ali, R. (2014). N-Acetylcysteine and metabotropic glutamate receptors: implications for the treatment of schizophrenia: a literature review. Psychiatr. Q. 85, 177-185. doi: 10.1007/s11126-0139281-3

Zhang, X., Li, Q., Wong, N., Zhang, M., Wang, W., Bu, B., et al. (2015). Behaviour and prefrontal protein differences in C57BL/6N and $129 \mathrm{X} 1 / \mathrm{SvJ}$ mice. Brain Res. Bull. 116, 16-24. doi: 10.1016/j.brainresbull.2015.05.003

Zhou, I. Y., Ding, A. Y., Li, Q., McAlonan, G. M., and Wu, E. X. (2012). Magnetic resonance spectroscopy reveals $\mathrm{N}$-acetylaspartate reduction in hippocampus and cingulate cortex after fear conditioning. Psychiatry. Res. 204, 178-183. doi: 10.1016/j.pscychresns.2012.09.010
Conflict of Interest Statement: The authors declare that the research was conducted in the absence of any commercial or financial relationships that could be construed as a potential conflict of interest.

Copyright (C) 2015 Durieux, Fernandes, Murphy, Labouesse, Giovanoli, Meyer, Li, So and McAlonan. This is an open-access article distributed under the terms of the Creative Commons Attribution License (CC BY). The use, distribution and reproduction in other forums is permitted, provided the original author(s) or licensor are credited and that the original publication in this journal is cited, in accordance with accepted academic practice. No use, distribution or reproduction is permitted which does not comply with these terms. 